\title{
A new fish-based index of biotic integrity for lowland rivers in Flanders (Belgium) - Corrigendum
}

\author{
Jan Breine ${ }^{1, *}$, Ericia Van den Bergh ${ }^{2}$, Gerlinde Van Thuyne ${ }^{1} \&$ \\ Claude Belpaire ${ }^{1}$ \\ ${ }^{1}$ Research Institute for Nature and Forest, Dwersbos 28, B-1630 Linkebeek, Belgium. \\ ${ }^{2}$ Research Institute for Nature and Forest, Havenlaan 88 bus 73, B-1000 Brussel, Belgium. \\ *Corresponding author: jan.breine@inbo.be
}

Breine J., VAn den Bergh E., Van Thuyne G. \& Belpaire C. (2021). A new fish-based index of biotic integrity for lowland rivers in Flanders (Belgium) - Corrigendum. Belgian Journal of Zoology 151: 205-207.

https://doi.org/10.26496/bjz.2021.94

This Corrigendum corrects an error in Table 2 that was published in Breine et al. (2021) on the pages 114-115: the line concerning the weatherfish Misgurnus fossilis (Linnaeus, 1758) on the page break was erroneously removed during publication and is added here.

\section{Reference}

Breine J., VAn den Bergh E., Van Thuyne G. \& Belpaire C. (2021). A new fish-based index of biotic integrity for lowland rivers in Flanders (Belgium). Belgian Journal of Zoology 151: 107-137. https://doi.org/10.26496/bjz.2021.89

Published on: 15 December 2021 


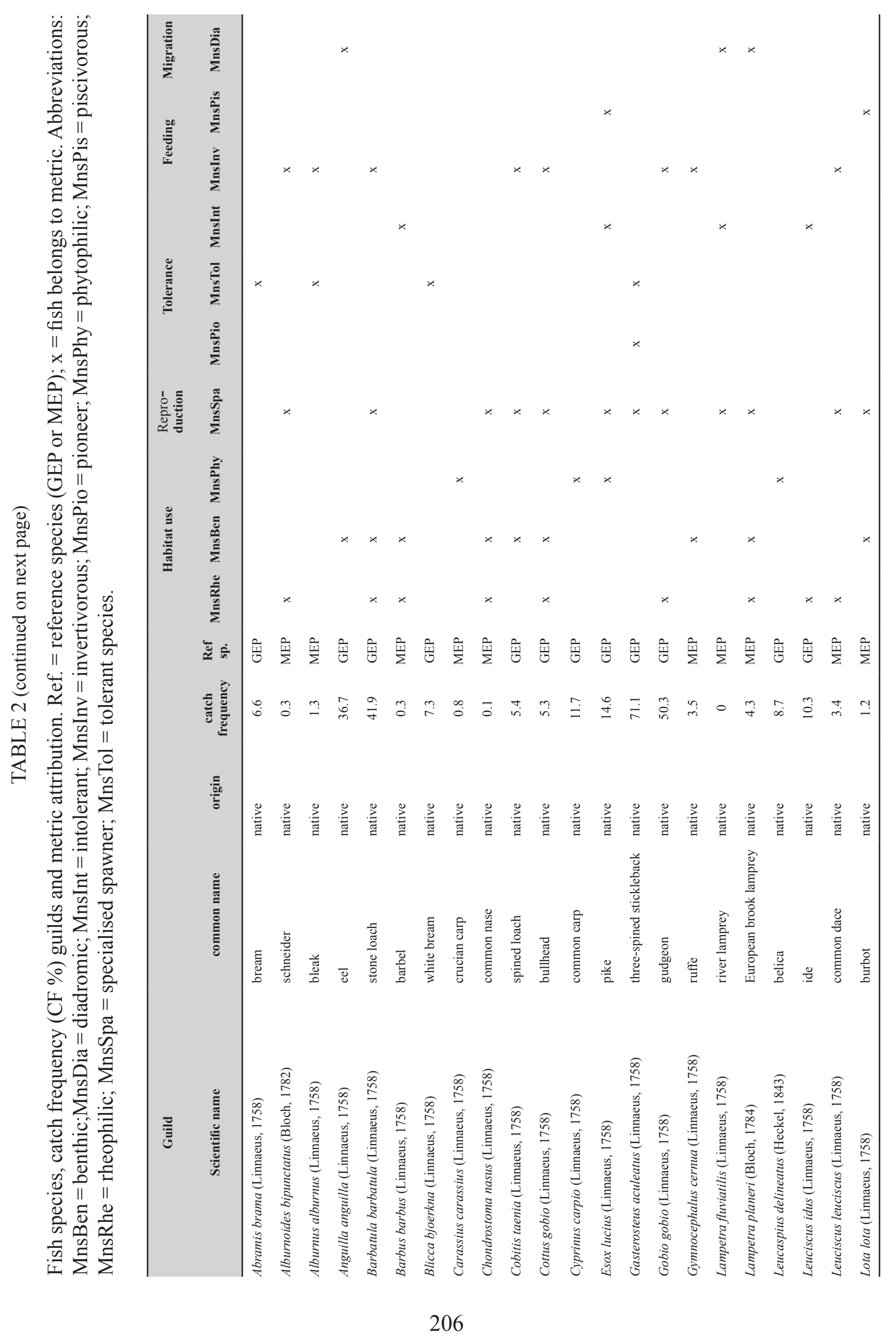




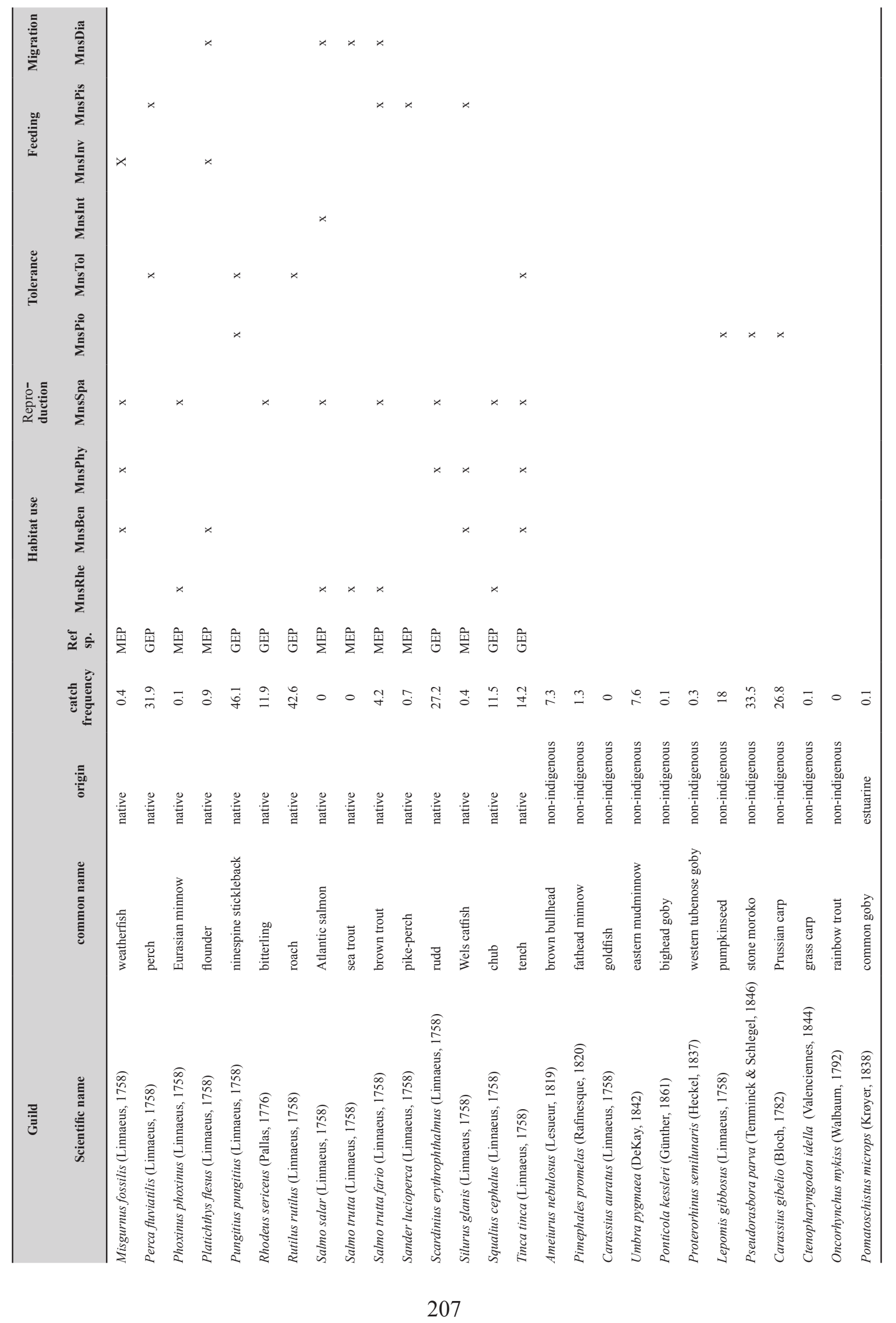

